\title{
Development of Market-prestige Model for Project Supervision
}

\author{
Zhongshan $\mathrm{Lu}^{1, \text { a }}$,Shuping Yang ${ }^{2, \mathrm{~b}}$ \\ ${ }^{1}$ School of Management,Hefei University of Technology, Hefei230009, China. \\ ${ }^{2}$ School of Civil Engineering,Hefei University of Technology, Hefei230009, China. \\ a1203215813@qq.com, b1094616037@qq.com
}

Keywords: Project supervision; Market-prestige model; Incentive mechanism

\begin{abstract}
The paper aims to investigate the incentive mechanism of project supervision organizers by using the market-prestige model. The results of two-stage game analysis indicated that the game process can be maintained at least two stages under asymmetric information. In Stage I, the efforts of project supervisors were motivated by the expectation of their job performance. In Stage II, the income of supervisors relied on the expectation of supervision performance in Stage I. The efforts of project supervisors were strictly over zero in Stage I with respect to their prestige. Hence, the prestige can be considered as parts of the explicit incentive contract in project supervision.
\end{abstract}

\section{Introduction}

As the major stakeholders of construction industry, project supervision organizers are monitored by the government. There is the game relationship between the governmental departments and project supervisors. On one hand, the government plays a dominant role and has the special power. On the other hand, project supervision organizations need to follow with the regulations and standards published by the government.

Macleod $(1983,1988)$ pointed out that the times of game process depends on the cost of quitting the market, when both players can independently choose the entry or exit. In consideration of high cost for supervisors to quit market and the special position of the government, the game can be lasted as repeated game. In order to improve the job performance of project supervision organizations, the government should study the long-term incentive mechanism of project supervisors.

Judicial system is maintained by the governmental coercive power. Prestige is established by both parties in the repeated game. Prestige mechanism depends on social regulation and contract, and its legislation is between the judicial system and market prestige. Prestige mechanism is the sum of regulations and rules for information disclosure, dispute resolution and fraud punishment among organizations in the market. The core of prestige model is used prestige as explicit incentive contract.

\section{Market-Prestige Model for Project Supervision Market}

Kreps et al. proved the impact of prestige on human behaviors in his KMRW model. Fama (1980) stated that incentive issues had been exaggerated in the agent principal literature. He emphasized the constraints of agent behavior in the market. Based on Fama' s agency market-prestige model, Holmstrom (1982) indicated that prestige should be considered as explicit incentive contract. Based on market-prestige model, this paper investigates the prestige in the project supervision market and the long-term incentive of supervisors by the government.

The game of project supervision organizations is hypothesized as two stages, and the job performance of supervisors is

$$
\pi_{t}=a_{t}+\theta+\mu_{t}, t=1,2
$$

and:

$\pi_{t}$ refers to the job performance of project supervisors; it is the common information.。

$a_{t}$ refers to the efforts of supervisors; it is the private information. 
$\theta$ refers to the supervision ability and changes depending on time.

$\mu_{t}$ refers to exogenous variables which are influenced by market uncertainty and other stakeholders.

$\theta$ and $\mu_{t}$ are normal independent distribution with the mean value of 0

( $\left.E \theta=E \mu_{t}=0\right)$ and the variance of $\operatorname{var}(\theta)=\sigma_{\theta}{ }^{2}, \quad \operatorname{var}\left(\mu_{t}\right)=\sigma_{\mu}{ }^{2} \cdot \mu_{1}$ and $\mu_{2}$ are independent variables with the covariance of $0\left(\operatorname{cov}\left(\mu_{1}, \mu_{2}\right)=0\right)$.

The risks of project supervisors are neutral. The discount rate is 0 when it is not considered the time value of financial capital. The utility function of project supervisors can be assumed as :

$$
U=w_{1}-c\left(a_{1}\right)+w_{2}-c\left(a_{2}\right)
$$

Where $w_{t}$ refers to income of supervisors. $c\left(a_{t}\right)$ refers to negative effect which is the strictly increasing convex function, and $c^{\prime}\left(a_{t}\right)=0$.

In the situation of symmetric information, the explicit incentive contact can be stated as $w_{t}=\pi_{t}-y_{0}$, where $y_{0}$ does not depend on $\pi_{t}$. Pareto can be realized and the risk cost is zero. The optimized efforts of project supervision organizations is illustrated as $c^{\prime}\left(a_{t}\right)=1, t=1,2$.

However, information is always dissymmetric in practice. Hence, the explicit incentive contract is assumed to be inexistence and project supervisors only get fixed income. If the game only happen once, supervisors would have no working motivation. Here, $c^{\prime}\left(a_{t}\right)=0, a_{t}=0$ 。

When the game lasts for two stages, project supervisors would consider prestige issue. In Stage II ( $\mathrm{t}=2$ ), the optimized efforts is $a_{2}=0$ 。 The income in Stage II is $w_{2}$, which depends on the expectation of supervision ability. The impact of $a_{1}$ on $\theta$ comes from the impact on $\pi_{1}$. The optimized efforts in Stage I is over zero.

The project supervision market is hypothesized as perfect competition. The income of project supervisors is thus equal to expected job performance.

$$
\begin{aligned}
& w_{1}=E\left(\pi_{1}\right)=E\left(a_{1}\right)=\overline{a_{1}} \\
& w_{2}=E\left(\pi_{2} / \pi_{1}\right)
\end{aligned}
$$

Where $E\left(a_{1}\right)$ is the expectation of the efforts of supervisors in Stage I.

$E\left(\pi_{2} / \pi_{1}\right)$ is the expectation of supervision performance in Stage II when the actual performance is $\pi_{1}$. Based on these hypothesis,

$$
E\left(\pi_{2} / \pi_{1}\right)=E\left(a_{2} / \pi_{1}\right)+E\left(\theta / \pi_{1}\right)+E\left(\mu_{2} / \pi_{1}\right)=E\left(\theta / \pi_{1}\right)
$$

Where $\pi_{1}$ only has impact on the supervision ability $\theta$ in Stage II, but no impact on efforts of project supervisors in Stage II $\left(a_{2}\right) E\left(\theta / \pi_{1}\right)$ refers to the expectation of supervision ability when the actual performance of project supervisors is $\pi_{1}$.

When the project supervision market follows rational expectation, $a_{1}$ equals to actual choice of project supervisors in the market equilibrium. When $\pi_{1}$ is known, the market achieves $\theta+\mu_{1}=\pi_{1}-\overline{a_{1}}$. The supervision market cannot separate the effect of supervision ability and exogenous variables. Apart from the effort of project supervisors, it is impossible to differentiate the results of $\pi_{1}$ or $\mu_{1}$. It can only deduce $\theta$ based on $\pi_{1}$.

$$
\tau=\frac{\operatorname{var}(\theta)}{\operatorname{var}(\theta)+\operatorname{var}\left(\mu_{1}\right)}=\frac{\sigma_{\theta}{ }^{2}}{{\sigma_{\theta}{ }^{2}+\sigma_{\mu}{ }^{2}}_{\tau}}
$$

Where $\tau$ is the ratio between the variance of $\theta$ and the variance of $\pi_{1}$.

According to rational expectation equation,

$$
E\left(\theta / \pi_{1}\right)=(1-\tau) E(\theta)+\tau\left(\pi_{1}-\overline{a_{1}}\right)=\tau\left(\pi_{1}-\overline{a_{1}}\right)
$$


Several findings can be summed:

(1) $(1-\tau) E(\theta)$ is uncertainty o exogenous variables $\mu$, which refers to $\left(1-\tau=\frac{\sigma_{\mu}{ }^{2}}{\sigma_{\theta}{ }^{2}+\sigma_{\mu}{ }^{2}}\right)$. It is independent with job performance of $\pi_{1}$.

(2) The expectation of $\theta$ is $E(\theta)$, which is determined by $\theta$ and $\mu$. Exogenous variables are not influenced by the job performance with the ratio of $1-\tau=\frac{\sigma_{\mu}{ }^{2}}{\sigma_{\theta}{ }^{2}+\sigma_{\mu}{ }^{2}} \cdot \pi_{1}-\overline{a_{1}}$ is determined by $\theta$ and $\mu_{1}$. The coefficient $\tau$ refers to the impact of $\theta$ on job performance of supervisors.

(3) The expectation of $\theta$ is illustrated as the means of $\pi_{1}-\overline{a_{1}}$ and $E(\theta)$, which is influenced by supervision ability. The more uncertainty the supervision ability is , the more the revision is. It is attributed that $\tau$ reflect the information of $\pi_{1}$ and $\theta$.

(4) When it is assumed no uncertainty $\left(\sigma_{\theta}{ }^{2}=0\right)$, the supervision market is not revised $(\tau=0)$. If the uncertainty tends to infinity, the supervision market totally depends on the judgment of $\theta$. Normally, $\tau \in[0,1]$

(5) Given $\tau>0, w_{2}=E\left(\theta / \pi_{1}\right)=\tau\left(\pi_{1}-\overline{a_{1}}\right)$, which means that the better performance in Stage I is, the higher incomes of supervisors in Stage II are.

$w_{1}$ and $w_{2}$ are substituted to the uniform equation of supervisors:

$$
U=\overline{a_{1}}-c\left(a_{1}\right)+\tau\left(a_{1}+\theta+\mu_{1}-\overline{a_{1}}\right)-c\left(a_{2}\right)
$$

First order condition of optimized performance of supervisors:

$$
c^{\prime}\left(a_{1}\right)=\tau>0 \Rightarrow a_{1}>0
$$

Hence, in the condition of information asymmetry, the game lasts for two stages. Although the optimized effort is less than the effort in information symmetry situation, the expectation of $\theta$ can also influence the actual working performance of supervisors. In consideration of prestige in Stage II, the effort in Stage I is strictly over zero. The prestige in supervision market can be treated as explicit incentive contract. The greater $\tau$ is, the stronger the prestige effects are. Prestige effects can resolve agent principle issue and work as explicit incentive contract ${ }^{[7]}$. The improvement of job performance is influenced by current efforts of supervisors and the judgment of supervision ability.

\section{Project Supervision Market Prestige Incentive}

Prestige incentive is defined that agent contributes to establish long-term prestige and principle chooses agents according to their prestige. There are several conditions to use prestige incentive in supervision market.

\subsection{Perfect competition in supervision market.}

Precondition to use prestige incentive is perfect completion in supervision market. The owner (principle) can independently choose the supervision organizations (agent) according to their prestige. It is important for project supervisors to emphasize on prestige. Perfect competition in supervision market is beneficial to reduce information asymmetry, increase mutual understanding between owners and project supervisors and further improve the job performance of supervisors.

\subsection{Development of effective information disclosure system}

The establishment of project supervisors' prestige depends on the judgment by owners. The judgment of owners depends on the effective information of supervision market. Hence, the governmental departments are suggested to develop effective information disclosure system to help owners choose appropriate supervisors and ensure the operation of prestige mechanism. 


\subsection{Development of evaluation criteria for project supervision market}

The precondition of prestige incentive mechanism is to objectively evaluate project supervisors. It is necessary to establish systematic and feasible evaluation criteria for supervision market and emphasize on the common interest and social interest.

\subsection{Establishment of ethics and media orientation}

The operation of prestige incentive mechanism depends on the ethics and value of the society. The government is encouraged to use media orientation and establish certified evaluation criteria for project supervision.

\subsection{Regulation development}

It is necessary to develop regulations for ensuring information disclosure, evaluation criteria and ethics orientation. The regulation development is beneficial to keep the long-term interest of qualified supervisors and costs of unqualified. It is needed for maintain the prestige mechanism and monitor mechanism.

\section{Conclusion}

This paper investigated the long-term incentive mechanism for project supervision organizations by using the market-prestige model. The analysis of the two-stage game indicated that the game between owners and supervisors lasted for two stages under the information asymmetric condition. The income of project supervisors in Stage II depends on the expectation of supervision ability, which is influenced by the efforts of supervisors in Stage I. The efforts of supervisors are strictly over zero in Stage I. Hence, prestige in supervision market is considered as explicit incentive contract. The efforts and job performance of supervisors influence the judgment of supervision ability. In supervision market, prestige can be developed as long term incentive. The project supervisors are therefore suggested to be honest and establish prestige in the market. The preconditions of supervision prestige incentive mechanism include perfect competition, information disclosure, evaluation criteria for supervision market, ethics orientation and regulation development.

\section{References}

[1] W. Macleod, 1983, The Role of Exit Cost in the theory of Cooperative Teams:A Theoretical perspective, Journal of Comparative Economics 17:521-529.

[2] W. Macleod, 1988, Equity, Efficiency, and Incentives in cooperative Teams, in Advances in the Economic Analysis of Participatory and Labor Managed Firms, Vol, 3:5-23.

[3] Fama, E., 1980, Agency problems and the theory of the Firm, Journal of political Economy 88:288-307.

[4] Holmstrom, B., 1982, Managerial Incentive problem-A Dynamic perspective, in Essays in Economic and Management in Honor of Lars Wahlbeck, Helsinki:Swedish School of Economics.

[5] Kreps, E.,Wilson.1982, Reputation and Imperfect Information,Journal of Economic Theory, 253-279.

[6] Meyer, M. and J. Vickers, 1994, Performance Comparison and Dynamic Incentive, mimeo,Nuffield College,Oxford University .

[7] Xuejun Huang. The incentive contact impact of prestige of construction contractors [J]. Industrial Engineering and Management, 2006, (2) : 74-77. 